\title{
The Experiences of Medical Students and Junior Doctors with Dyslexia: A Survey Study
}

\author{
John L. Anderson ${ }^{1} \&$ Sebastian C. K. Shaw ${ }^{2}$ \\ ${ }^{1,2}$ Department of Medical Education, Brighton and Sussex Medical School, University of Brighton, \\ Falmer, Brighton, United Kingdom \\ Correspondence: Sebastian C. K. Shaw, Brighton and Sussex Medical School, University of Brighton, \\ Falmer, Brighton, United Kingdom. \\ Email: s.shaw2@bsms.ac.uk
}

doi: 10.23918/ijsses.v7i1p62

\begin{abstract}
Little research exists concerning dyslexia in medical education. A qualitative study highlighted issues such as bullying and a lack of support. This project aimed to quantify those findings. An online survey was sent to junior doctors in parts of the United Kingdom. Seventy-five participated. Most (53\%) were diagnosed with dyslexia at university / medical school. Most reported that dyslexia impacted upon their selfimage $(59 \%)$ and self-esteem $(\mathbf{7 3 \%})$. Nearly half $(\mathbf{4 6 \%})$ felt it influenced their career pathway choices within medicine. Participants reported bullying at medical school - from peers $(24 \%)$, from academic teachers $(14 \%)$, and from clinical teachers $(27 \%)$; and also at work - from peers $(25 \%)$, from academic teachers $(13 \%)$, and from clinical teachers $(23 \%) .88 \%$ reported that foundation schools provided no support, $92 \%$ that NHS Trusts provided none, and $90 \%$ that their deaneries provided none. The sorts of supports which seemed to be lacking were "psychological" or "pastoral" supports.
\end{abstract}

Keywords: Medical Students, Doctors, Dyslexia, Specific Learning Difficulties, Mixed Methods

\section{Introduction}

Dyslexia has been defined as ".... a continuum of difficulties in learning to read, write and/or spell, which persist despite the provision of appropriate learning opportunities. These difficulties often do not reflect an individual's cognitive abilities and may not be typical of performance in other areas." (Dyslexia Scotland, 2015). It is an often-misunderstood condition within medicine (Shaw \& Anderson, 2017b). It is primarily known to impact upon individuals' speed and/or accuracy of reading and/or writing (Davis Dyslexia Association International, n.d.; Moody, n.d.; Shaw \& Anderson, 2017b; Shrewsbury, 2016; Smythe \& Everatt, 2001). However, it also impacts upon organisational skills, short-term memory, and information processing abilities (Davis Dyslexia Association International, n.d.; Moody, n.d.; Shaw \& Anderson, 2017b; Shrewsbury, 2016; Smythe \& Everatt, 2001).

Dyslexia is one of the Specific Learning Difficulties (SpLDs) as defined in the United Kingdom (UK) (Siegel, 2006; Walker \& Shaw, 2018). As such, it is protected under the UK Equality Act of 2010 (Great Britain, 2010). Employers are therefore required to make any reasonable adjustments that are deemed necessary to enable individuals with dyslexia to perform their role (Homer, 2017). Identifying potential adjustments may however prove challenging (Shaw, 2018). 
Estimates put the prevalence of dyslexia at around $10 \%$ in the general population (Dyslexia International, n.d.). In 2007 the BMA reported that $1.7 \%$ of new entrants to medical schools had SpLDs. It is known that dyslexia is the most prevalent SpLD (Homer, 2017). Assuming success at medical school, these students go on to work as junior doctors within the UK National Health Service. It is therefore imperative that these doctors are both understood and supported in their clinical practice to promote both their successful professional development and patient safety.

SS (the second author) has dyslexia. This is something that he is open and honest about with his peers and his employers. His personal experiences formed the drive for an initial qualitative study of medical students' experiences of dyslexia (Shaw \& Anderson, 2017a, 2018), and now for this study. There was very little published about dyslexia in medical students or doctors. Searchers found three studies of the impact of dyslexia on the performance of medical students in exams (Gibson \& Leinster, 2011; McKendree \& Snowling, 2011; Ricketts, Brice, \& Coombes, 2010), and one study of junior doctors lived experiences (Newlands, Shrewsbury, \& Robson, 2015). These studies showed the effectiveness of compensations (such as extra time) in exams and showed that, with them, medical students with dyslexia (MSWD) can perform as well as their non-dyslexic peers (Gibson \& Leinster, 2011; McKendree \& Snowling, 2011; Ricketts et al., 2010; Shaw, Malik, \& Anderson, 2017).

Several studies had reported on the experiences of other healthcare students (Child \& Langford, 2011; Morris \& Turnbull, 2006; Murphy, 2009; Murphy, 2011). These studies of other healthcare students highlighted difficulties encountered by students with dyslexia, including a lack of confidence, a lack of perceived support, and feelings of low self-worth or sorrow (Child \& Langford, 2011; Morris \& Turnbull, 2006; Murphy, 2009; Murphy, 2011). These findings have also been reported in some of our own research into the experiences of medical students and junior doctors with dyslexia (JDWD) (Shaw \& Anderson, 2017a, 2018; Shaw, Anderson, \& Grant, 2016).

We embarked upon a programme of in-depth qualitative research to elicit and report the lived experiences of MSWD and JDWD. This began with an autoethnographic study of SS's personal experiences (Shaw et al., 2016), followed by a qualitative study of junior doctors' experiences whilst at medical school (Shaw \& Anderson, 2017a, 2018). This study identified the following themes (Shaw \& Anderson, 2018):

- "Emotional impact" - including "isolation, self- consciousness, [and] hopelessness/helplessness".

- "Others' reactions" - including "bullying and rejection, stonewalling, [and the] impact on disclosure".

- "The system" - including "stigmatization, competition, [and] pride".

- "Supports: the good, the bad, and the wanted" - including "pastoral support, paradoxical support, [and] others to talk to".

- "Essays, exams, and exasperation" - including "dyslexia- friendly assessments, negative assessments, [and a] lack of exam support".

- "Me, myself, and my dyslexia" - including the "positive aspects [of dyslexia], [and] the association of dyslexia and the self".

This survey aimed to quantify our earlier findings. 


\section{Methods}

The data from our initial qualitative (pilot) study (Shaw \& Anderson, 2017a, 2018) informed the development of a Surveymonkey TM questionnaire. The survey was piloted by SS prior to being sent out. It was then advertised (with a web link to the survey) in the eBulletins of five foundation schools in the South of England and was emailed directly to all General Practice trainees within a single Deanery in the South of England. This ensured a wide representation of medical schools. Interested JDWD were invited to access and complete the online survey. Two reminders were sent out before the survey closed.

Here we present an analysis of the data relating to their reported experiences through medical school and into work. When participants chose to skip some of the questions, these were omitted in calculations involving the responses to those questions. The test of the significance of the difference between proportions was used to check the significance between percentages in sub-groups in the survey (Bradford Hill, 1977).

Data concerning the prescribing experiences and practices of our participants are to be analysed and reported separately.

\section{Results}

Seventy-seven individuals responded. Two were discarded - a medical student and a fully qualified General Practitioner. Most, (69\%) were female. Most (87\%) were from the UK with English as their first language (97\%). Most (80\%) were aged between 21 and 30. Most (53\%) had their dyslexia diagnosed whilst at university. Interestingly, of those diagnosed before medical school (39\%), most (88\%) felt that this early diagnosis was helpful.

\subsection{Their Dyslexia}

Their reported dyslexic difficulties are shown in Table 1. The most commonly-reported difficulties were: slow reading speed (70\%); poor spelling (61\%); struggling to articulate thoughts accurately onto paper (54\%); problems with revising or working with distractions - e.g. music, other people or televisions (49\%); inability to retain spoken information e.g. lectures (46\%); being easily distracted by noises and other people (45\%); slow writing speed (43\%); confusion with 'Left' and 'Right' (43\%); difficulty absorbing spoken information in lectures $(42 \%)$; missing out or repeating words when writing things (42\%); difficulty reading out loud (39\%); difficulty reading from screens (36\%); poor attention span (35\%); taking longer than others to grasp concepts (35\%); thinking differently to other people (32\%); struggling with written material (32\%); and difficulty remembering information given over the phone (30\%). For most of these, women reported them more often than men but only two - confusion with 'Left' and 'Right' and poor spatial awareness - were significantly different. 
Table 1: Difficulties experienced as a result of dyslexia, by gender

\begin{tabular}{|c|c|c|c|}
\hline & \multicolumn{3}{|c|}{ Gender } \\
\hline & Males & Females & All \\
\hline Difficulty: & $\%$ & $\%$ & $\%$ \\
\hline $\begin{array}{l}\text { Inability to retain spoken } \\
\text { information e.g. lectures. }\end{array}$ & 32 & 53 & 46 \\
\hline Poor spelling & 68 & 57 & 61 \\
\hline Difficulty reading out loud & 32 & 43 & 39 \\
\hline Slow reading speed & 77 & 66 & 70 \\
\hline $\begin{array}{l}\text { Difficulty understanding spoken } \\
\text { information }\end{array}$ & 18 & 17 & 17 \\
\hline Poor attention span & 36 & 34 & 35 \\
\hline Difficulty reading from screens & 23 & 43 & 36 \\
\hline Slow writing speed & 50 & 40 & 43 \\
\hline $\begin{array}{l}\text { Taking longer than others to grasp } \\
\text { concepts }\end{array}$ & 23 & 40 & 35 \\
\hline Difficulty with calculations & 14 & 34 & 28 \\
\hline $\begin{array}{l}\text { Difficulty absorbing spoken } \\
\text { information in lectures }\end{array}$ & 36 & 45 & 42 \\
\hline $\begin{array}{l}\text { Easily distracted by noises and } \\
\text { other people }\end{array}$ & 32 & 51 & 45 \\
\hline Struggling with written material & 32 & 32 & 32 \\
\hline $\begin{array}{l}\text { Struggling to commit things to } \\
\text { paper }- \text { e.g. sentences not phrased } \\
\text { as intended }\end{array}$ & 50 & 45 & 46 \\
\hline $\begin{array}{l}\text { Struggling to articulate thoughts } \\
\text { accurately onto paper }\end{array}$ & 55 & 53 & 54 \\
\hline $\begin{array}{l}\text { Missing out or repeating words } \\
\text { when writing things }\end{array}$ & 27 & 49 & 42 \\
\hline $\begin{array}{l}\text { Unable to learn from lectures and } \\
\text { any other forms of teaching - in } \\
\text { any circumstances }\end{array}$ & 5 & 15 & 12 \\
\hline $\begin{array}{l}\text { Problems with revising or working } \\
\text { with distractions }\end{array}$ & 41 & 53 & 49 \\
\hline Confusion with 'Left' and 'Right'* & 9 & 60 & 43 \\
\hline Poor spatial awareness* & 0 & 28 & 19 \\
\hline
\end{tabular}




\begin{tabular}{|l|c|c|c|}
\hline $\begin{array}{l}\text { Thinking differently to other } \\
\text { people }\end{array}$ & 45 & 26 & 32 \\
\hline $\begin{array}{l}\text { Difficulty reading black text on a } \\
\text { white background }\end{array}$ & 9 & 21 & 17 \\
\hline Difficulty reading certain fonts & 14 & 6 & 30 \\
\hline $\begin{array}{l}\text { Difficulty remembering } \\
\text { information given over the phone }\end{array}$ & 18 & 36 & 7 \\
\hline $\begin{array}{l}\text { Struggling to understand and } \\
\text { operate computers }\end{array}$ & 5 & 9 & 23 \\
\hline $\begin{array}{l}\text { Struggling to understand written } \\
\text { questions in exams }\end{array}$ & 32 & 19 & 75 \\
\hline N $(=100 \%)^{1}$ & 23 & 52 & \\
\hline $\begin{array}{l}* \\
1\end{array}$ NBese differences were significant at the P<0.05 level. \\
vary.
\end{tabular}

\subsection{Experiences whilst at Medical School}

The most commonly reported reactions were feeling stupid (79\%), a sense of inadequacy (78\%) anxiety $(60 \%)$, shame (56\%), depression (40\%), and isolation (38\%). Female students were more likely than males to feel the impact of these (Table 2). We found no significant differences in the emotional impacts reported when the results of those diagnosed with dyslexia before medical school were compared to the results of those who were diagnosed at or since medical school.

Bullying was reported - from peers (24\%), from academic teachers (14\%), and from clinical teachers in practice $(27 \%)$. Women were significantly more likely to report bullying/ridicule from clinical teachers in practice. Problems around disclosure were reported by 43\%. Again, there were significant gender differences.

Most reported that their dyslexia had an impact upon their self-image (59\%). Self-esteem (73\%) and peers' reactions (55\%). Almost half (46\%) felt it had influenced their subsequent career pathway choices, whilst $32 \%$ felt it had affected personal relationships. Again, females were more likely to report such impacts than males.

"Peers can think that you are not working hard or are stupid when you are unable to remember things. It can also make people feel that you don't care if you don't remember what they have said"

"Certainly I am wary of choosing psychiatry/ public health (both of which I enjoy) owing to the very large time spent writing and reading long reports which I would find so incredibly hard (even if to some degree find it satisfying). This fear is pushing me into 
'quick' reaction/ active medicine e.g. A\&E which of course has a huge huge impact on my future lifestyle. This is one of the main reasons I cannot decide on a career path."

Fifteen percent felt that their dyslexia impacted upon their selection for medical school - none of the comments reflected any thoughts of positive discrimination. Overall, 90\% felt that their dyslexia had an impact on their achievement at medical school - 22\% to a large or massive amount. Comparatively, $75 \%$ felt it had an impact on their transition to medical practice.

"I feel I worked harder than others to get to the level I did."

Table 2: Effects of dyslexia whilst at medical school, by gender

\begin{tabular}{|l|c|c|c|c|c|c|}
\hline Effect of dyslexia: & \multicolumn{3}{|c|}{ At medical school: } & \multicolumn{3}{c|}{ At/since foundation school: } \\
\hline & Male & Female & All & Male & Female & All \\
\hline Shame & 48 & 59 & 55 & 28 & 63 & $52^{*}$ \\
\hline Inadequacy & 53 & 89 & $77^{*}$ & 50 & 72 & 66 \\
\hline Depression & 19 & 47 & $38^{*}$ & 6 & 37 & $28^{*}$ \\
\hline Anxiety & 38 & 73 & 62 & 33 & 70 & $59^{*}$ \\
\hline Isolation & 24 & 45 & 38 & 17 & 37 & 31 \\
\hline Feeling Stupid & 71 & 84 & 80 & 44 & 84 & 72 \\
\hline $\begin{array}{l}\text { Bullying/Ridicule from } \\
\text { peers }\end{array}$ & 24 & 23 & 23 & 11 & 31 & 25 \\
\hline $\begin{array}{l}\text { Bullying/Ridicule from } \\
\text { Teachers }\end{array}$ & 10 & 19 & 16 & 6 & 17 & 13 \\
\hline $\begin{array}{l}\text { Bullying/Ridicule from } \\
\text { clinical teachers in } \\
\text { practice }\end{array}$ & 14 & 37 & $30^{*}$ & 6 & 31 & $23^{*}$ \\
\hline \begin{tabular}{l} 
Issues of disclosure \\
\hline N (=100\%)
\end{tabular} & 14 & 57 & $43^{*}$ & 6 & 45 & $33^{*}$ \\
\hline $\begin{array}{l}* \\
1\end{array}$ & 23 & 52 & 75 & 23 & 52 & 75 \\
\hline \\
vary.
\end{tabular}

\subsection{Supports at Medical School}

A variety of supports were mentioned for different types of assessments. Extra time for exams was the most commonly reported and was felt to be helpful by $52 \%$. IT hardware (e.g. a laptop) was felt to be helpful by $48 \%$. Separate rooms for dyslexic students to sit their exams was appreciated by $37 \%$ - but was felt to make them visible by $3 \%$. The supports which respondents were most likely to have wanted were peer support groups for dyslexia (33\%), the facility to write things down in exams (OSCEs) (26\%), other aids in exams (28\%), and pastoral Support (14\%) - which has appreciated by $30 \%$.

The following comments reflect respondents' desires and satisfactions:

"Extra time for exams." 


\section{"I would have liked an opportunity for tutoring." \\ "essay support and structure teaching." \\ "Clinical teachers being aware and understanding what dyslexia is." \\ "The student advice service encouraging me to take the test and help me get over the stigma I felt surrounding my problems."}

Only $7 \%$ reported their level of support whilst at medical school to be "none at all"; $22 \%$ said it was either "a large amount" $(20 \%)$ or "hugely supportive" $(2 \%)$.

\subsection{Experiences as Junior Doctors}

Most reported feeling stupid (72\%), a sense of inadequacy (66\%) anxiety (59\%), shame (52\%). Depression (28\%), and isolation (31\%) were less common. Female participants were more likely than males to feel the impact of these (Table 2).

Bullying was reported - from peers (25\%), from academic teachers (13\%) and from clinical teachers in practice $(23 \%)$. Issues around disclosure were reported by $43 \%$. Again, Female participants were more likely to report bullying from teachers and issues around disclosure. Most (84\%) felt that their dyslexia had continued to have an impact on their education.

\subsection{Supports for Junior Doctors}

In contrast to the supports provided to undergraduates, $88 \%$ reported that foundation schools had provided "None at all", 90\% reported that their Deaneries provided "None at all", and 92\% that NHS Trusts has provided "None at all".

\section{Discussion}

\subsection{Gender Differences}

Female doctors were more likely to participate in this survey than males - two-thirds of our respondents were female. This was anticipated from the results of earlier work. However, it was, perhaps, surprising to note the differences in the impact and issues reported by females and males. Females tended to be consistently more likely to report issues and the impacts of their dyslexia than males. This is worthy of further research to ascertain the reasons for these differences.

The fact that most (58\%) reported being diagnosed at or since university suggests that the BMA estimate of $1.7 \%$ of new entrants to medical schools having SpLDs, is likely to be an underestimate of the prevalence of dyslexia in medical students.

\subsection{Effects of Dyslexia}

The difficulties reported whilst at medical school which were associated with dyslexia included the common ones such as poor spelling, slow reading and writing. They also included others which suggested a more complex picture of dyslexia than is commonly thought of, and which illustrate the breadth of the impact of dyslexia. These included things which impact upon the learning process such as an inability to 
retain or absorb spoken information e.g. in lectures; poor attention span; struggling to articulate thoughts accurately onto paper; being easily distracted by noises and other people; and thinking differently to other people.

Our participants also reported that there were negative impacts upon their feelings, resulting in a sense of shame, inadequacy, feeling stupid, depression, anxiety, and for some - a sense of isolation. These, in turn, impacted upon their self-image and esteem, their peers' image of them and their own personal experiences. They felt it had affected their academic performances, their career choices and their progression into work.

The effects of dyslexia whilst at foundation school mirrored their experiences whilst at medical school they did not disappear.

\subsection{Bullying}

It is a sad World in which people are bullied as a result of their disabilities. This is confirmed by our respondents, $24 \%$ reported bullying by peers at medical school; $14 \%$ were bullied by teachers; and $27 \%$ by clinical teachers. Female trainees were more likely than male trainees to report bullying from clinical teachers. In a previous paper, we reported some accounts of students being accused of being "fake dyslexics" by peers. We also reported the upset caused by clinical teachers bullying trainee dyslexics. Again, it seems to be female students and junior doctors who bear the brunt of clinical teachers' bullying. The whole essence of bullying could benefit from a wider public debate.

\subsection{Supports}

A previous review of the literature showed that there was general consensus about the effectiveness of providing "accommodations" for MSWD in different assessments (Shaw et al., 2017). The agreement was that by providing such things as extra time in exams, MSWD performed on a par with other medical students (Shaw et al., 2017). There seemed to be some variation in the provision of supports - something which we are investigating in another study. Most participants reported extra time in MCQ, EMQ and SAQ exams. Only $42 \%$ reported extra time for essays. About half thought that having a separate room for exams was helpful - although some reported it increased their public visibility. Forty-eight percent thought IT hardware was useful.

The sorts of supports which seemed to be lacking were "psychological" or "pastoral" supports. Along with peer support groups, there seemed to be quite a demand for these. So, whilst we may be getting it right by providing extra time in exams and providing special computer hardware, we may be letting students down when it comes to providing therapeutic support. Where, for example, might someone go if they experience negative feelings as a result of bullying? Where is the support for those $38 \%$ who reported depression as a result of their experiences of having dyslexia in medical school?

\subsection{Limitations}

Due to the nature of this study - a survey without a control - it is not possible to conclude that dyslexia is the causative factor of the experiences reported. It is also worth noting that our participants were all working within the South of England (although they came from a wide variety of medical schools). Experiences elsewhere may be different. 


\section{Conclusions}

In this survey of junior doctors, we asked about their experiences of having dyslexia in medical school and in clinical practice. Our results give figures to what other (qualitative) studies have shown about medical students' experiences, and what other healthcare students have reported.

Of note are the reported gender differences. These show that our female respondents seem to have a harder time with their dyslexia and perceived bullying than their male counterparts

Although there were some supports available, there seemed to be large variations in these. Extra time and computer hardware were acknowledged as being useful. However, there was a "black hole" when it came to pastoral support - it was almost completely missing. We are currently in the process of researching the variation in supports offered for MSWD across the UK. More research may also be needed to identify the most effective supports for medical students and junior doctors with dyslexia.

This is the first quantitative work of this nature. Additional research, on a national level would be welcomed to corroborate our findings. We would welcome expressions of interest from other academics in this field.

\section{References}

Bradford Hill, A. (1977). A short textbook of medical statistics. London: Hodder and Stoughton.

Child, J., \& Langford, E. (2011). Exploring the learning experiences of nursing students with dyslexia. Nursing Standard, 25(40), 39-46.

Davis Dyslexia Association International. (n.d.). Common characteristics of adult dyslexia [online]. Retrieved on 23 July, 2016 from http://www.dyslexia.com/about-dyslexia/signs-ofdyslexia/common-characteristics-of-adult-dyslexia/

Dyslexia International. (n.d.). The problem [online]. Retrieved on 9 August 2019 from http://www.dyslexia-international.org/the-problem/

Dyslexia Scotland. (2015). Definition of dyslexia [online]. Retrieved on 7 August, 2019 from https://www.dyslexiascotland.org.uk/definition-dyslexia

Gibson, S., \& Leinster, S. (2011). How do students with dyslexia perform in extended matching questions, short answer questions and observed structured clinical examinations? Adv Health Sci Educ Theory Pract, 16(3), 395-404. doi:10.1007/s10459-011-9273-8

Great Britain. (2010). Equality Act 2010. London: Stationary Office. Retrieved on 19 October, 2019 from http://www.legislation.gov.uk/ukpga/2010/15/pdfs/ukpga_20100015_en.pdf

Homer, R. (2017). The impact of dyslexia on nursing students in higher education. Journal of Health and Social Care Improvement, 1(3), 15-22.

McKendree, J., \& Snowling, M. J. (2011). Examination results of medical students with dyslexia. Med Educ, 45(2), 176-182. doi:10.1111/j.1365-2923.2010.03802.x

Moody, S. (n.d.). Dyslexia and dyspraxia in adulthood: information for doctors and psychotherapists [online]. Retrieved on 1 August, 2016 from https://www.patossdyslexia.org/assets/Documents/Dyslexiainfofordoctorstherapists.pdf?1390236174

Morris, D., \& Turnbull, P. (2006). Clinical experiences of students with dyslexia. Journal of Advanced Nursing, 54(2), 238-247. doi:10.1111/j.1365-2648.2006.03806.x

Murphy, F. (2009). The clinical experiences of dyslexic healthcare students. Radiography, 15(4), 341344.

Murphy, F. (2011). On being dyslexic: student radiographers' perspectives. Radiography, 17(2), 132138. 
Newlands, F., Shrewsbury, D., \& Robson, J. (2015). Foundation doctors and dyslexia: a qualitative study of their experiences and coping strategies. Postgrad Med J, 91(1073), 121-126. doi:10.1136/postgradmedj-2014-132573

Ricketts, C., Brice, J., \& Coombes, L. (2010). Are multiple choice tests fair to medical students with specific learning disabilities? Adv Health Sci Educ Theory Pract, 15(2), 265-275. doi:10.1007/s10459-009-9197-8

Shaw, S. C. K. (2018). Learned helplessness in doctors with dyslexia: time for a change in discourse? Nurse Education in Practice, 32, 99-100.

Shaw, S. C. K., \& Anderson, J. L. (2017a). Doctors with dyslexia: a world of stigma, stonewalling and silence, still? MedEdPublish, 6(1), 29.

Shaw, S. C. K., \& Anderson, J. L. (2017b). Twelve tips for teaching medical students with dyslexia. Med Teach, 39(7), 686-690.

Shaw, S. C. K., \& Anderson, J. L. (2018). The experiences of medical students with dyslexia: an interpretive phenomenological study. Dyslexia, 24(3), 220-233.

Shaw, S. C. K., Anderson, J. L., \& Grant, A. J. (2016). Studying medicine with dyslexia: a collaborative autoethnography. Qual Rep., 21(11), 2036-2054.

Shaw, S. C. K., Malik, M., \& Anderson, J. L. (2017). The exam performance of medical students with dyslexia: a review of the literature. MedEdPublish, 6(3).

Shrewsbury, D. (2016). Dyslexia in general practice education: considerations for recognition and support. Educ Prim Care. doi:10.1080/14739879.2016.1194170

Siegel, L. S. (2006). Perspectives on dyslexia. Paediatr Child Health, 11(9), 581-587.

Smythe, I., \& Everatt, J. (2001). Adult checklist [online]. Retrieved on 23 July, 2016 from http://www.bdadyslexia.org.uk/common/ckeditor/filemanager/userfiles/Adult-Checklist.pdf

Walker, E. R., \& Shaw, S. C. K. (2018). Specific learning difficulties in healthcare education: the meaning in the nomenclature. Nurse Education in Practice, 32, 97-98. 